\title{
Alteration of the Solubility of 4,4'-Hexafluoroisopropylidene Diphtalic Anhydride-4,4-Oxydianline Polyimide by Experimental and Theoretical Methods
}

\author{
Kyoung-Yong CHUN, Jong-Ho PARK, Soon-Ho JANG, Shul-Yong GUN, and Yung-il JoE ${ }^{\dagger}$ \\ School of Chemical Engineering and Biotechnology, Yonsei University, \\ Seodamun-Ku, Sinchon-Dong, Seoul 120-749, Korea
}

(Received November 1, 1999)

\begin{abstract}
Alteration of the solubility of 4,4'-Hexafluoroisopropylidene diphtalic anhydride-4,4-oxydianline polyimide was investigated through experimental (the solubility experiments and equilibrium swelling) and theoretical (group contribution method by Fedors). In solubility experiments, total solubility obtained by a two dimensional representation $\left(\delta_{\mathrm{v}} v \mathrm{~s}\right.$. $\delta_{\mathrm{h}}$ diagram $)$ was $21.23\left(\mathrm{~J} \mathrm{~cm}^{-3}\right)^{1 / 2}$. The range of total solubility determined from the equilibrium swelling method was between 22.71 and $22.99\left(\mathrm{~J} \mathrm{~cm}^{-3}\right)^{1 / 2}$. The total solubility of 6 FDA-4,4'ODA polyimide calculated from the group contributions was $22.22\left(\mathrm{~J} \mathrm{~cm}^{-3}\right)^{1 / 2}$. The difference of solubility is slightly existed between experimental and theoretical method, but showed very good agreement.

KEY WORDS 4,4'-Hexafluoroisopropylidene Diphtalic Anhydride-4,4-Oxydianline Polyimide / Group Contributions / Solubility /
\end{abstract}

Polyimides have outstanding properties : as thermal stability, high mechanical strength, high modulus, and superior chemical resistance. Generally, most polyimides are processed in the form of their poly amic acid as precursor of polyimide, which are then thermally or chemically converted to the imide structure. However, several polyimides soluble in organic solvents have been produced. ${ }^{1,2}$ Most results of organic soluble polyimides indicate only the physical properties, but little information is available on solubility. In researching of solubility behavior, solubility has helped to solve various specific considerations related to ternary or binary phase interactions. Recently, polyimides have been used in membrane materials with various structure types. ${ }^{3-6}$ In the porous membrane preparation, one physical property is the solubility difference in the ternary phase system: the polymer-solvent, the polymer-nonsolvent, and the solvent-nonsolvent interaction. ${ }^{7-10}$

Hilderbrand and $\mathrm{Scott}^{11}$ developed the solubility parameter theory, in which the solubility of a component $i$ for the liquid of low molecular weight, $\delta_{\mathrm{i}}$, is defined as follows :

$$
\delta_{\mathrm{i}}=\left(\frac{E_{\mathrm{Coh}, \mathrm{i}}}{V_{\mathrm{i}}^{0}}\right)^{1 / 2}=\left(\frac{\Delta U_{\mathrm{V}, \mathrm{i}}}{V_{\mathrm{i}}^{0}}\right)^{1 / 2}=(C E D)^{1 / 2}
$$

where $E_{\mathrm{Coh}, \mathrm{i}}$ is the cohesive energy of a component $\mathrm{i}$ and $\Delta U_{\mathrm{V}, \mathrm{i}} / V_{\mathrm{i}}^{0}$ is the energy of vaporization $(\Delta U)$ per unit volume of $\mathrm{i}\left[\mathrm{J} \mathrm{cm}^{-3}\right]$, or cohesive energy density (CED). Therefore, solubility can be calculated from the heat of evaporation (i.e., cohesive energy). This theory only accounts for the contributions of the mixing enthalpy to the free energy of mixing, and predicts that how a polymer is soluble according to the solubility difference between a polymer and a solvent. For many liquids and polymers, the cohesive energy is dependent on interactions between the polar forces, the dispersion forces, and hydrogen bonding. In these cases, solubility can be de- fined as the total cohesive energy. The following equation gives solubility.

$$
\delta_{\mathrm{t}}^{2}=\delta_{\mathrm{d}}^{2}+\delta_{\mathrm{p}}^{2}+\delta_{\mathrm{h}}^{2}
$$

where $\delta_{\mathrm{d}}, \delta_{\mathrm{p}}$, and $\delta_{\mathrm{h}}$ are contribution of the dispersion forces, polar forces, and hydrogen bonding forces toward solubility, respectively. For a substance of low molecular weight, $E_{\text {Coh }}$ was considered as an additive property by Dunkel, ${ }^{12}$ who derived group contributions for the cohesive energy of liquids at room temperature. Hayes, ${ }^{13} \mathrm{Di}$ Benedetto, ${ }^{14}$ Hoftyzer, ${ }^{15}$ and Fedors ${ }^{16}$ applied Dunkel's method to polymer characterization.

Beerbower et $a l .{ }^{17}$ expressed hydrogen bonding energy by the hydrogen bonding number $\Delta v$. This quantity was defined by Gordy and Stanford ${ }^{18}$ as the shift of the infrared absorption band in the $4 \mu \mathrm{m}$ range when a given liquid is added to a solution of deuterated methanol in benzene. Hansen ${ }^{19}$ determined experimentally the solubility of a number of polymers using various solvents. $\delta_{\mathrm{d}}$ of a solvent was assumed equal to that of a non-polar substance of about the same chemical structure. This assumption permitted calculation of $\delta_{\mathrm{p}}^{2}+\delta_{\mathrm{h}}^{2}=\delta^{2}-\delta_{\mathrm{d}}^{2}(=$ $\delta_{\text {a). }}^{2}$. However, Hansen's method has the disadvantage that three-dimensional structures are necessary for graphical representation of the interaction between polymers and solvents. This method is not efficient in comparison to two-dimensional method for practical applications. Bagley et al. ${ }^{20}$ concluded that the effects of $\delta_{\mathrm{d}}$ and $\delta_{\mathrm{p}}$ show close similarity, while the effect of $\delta_{\mathrm{h}}$ is quite different in thermodynamic consideration. Accordingly, they introduced the parameter.

$$
\delta_{\mathrm{v}}=\sqrt{\delta_{\mathrm{d}}^{2}+\delta_{\mathrm{p}}^{2}}
$$

This leads to a diagram in which $\delta_{\mathrm{v}}$ and $\delta_{\mathrm{h}}$ are plotted on the axes, which seems most efficient to represent the

\footnotetext{
${ }^{\dagger}$ To whom correspondence should be addressed (Tel: 822-361-2755, Fax: 822-312-6401, E-mail: kychun@bubble.yonsei.ac.kr).
} 
polymer-solvent interaction.

Experimental determinations of total solubility include the viscosity and equilibrium swelling method. Mangaraj et al. ${ }^{21}$ plotted the intrinsic viscosity against total solubility of solvents. This method requires some soluble solvents close in solubility. Chapiro et $a l^{22}$ and Fuehrer $^{23}$ used the equilibrium swelling method to determine the total solubility parameter.

In this paper, the solubility behavior of $6 \mathrm{FDA}-4,4$ ODA polyimide film widely used as a innovative material is investigated through solubility measurements. Solubility experiments and equilibrium swelling method were used to determine total solubility. Theoretically, the total solubility of 6 FDA-4,4'ODA polyimide film was calculated by the group contributions of Fedors.

\section{EXPERIMENTAL}

\section{Materials}

4,4'-Hexafluoroisopropylidene diphtalic anhydride (6FDA, CHRISKEV) and 4,4-oxydianline (4,4'ODA, Aldrich) were purified by vacuum sublimation before use in polymerization. The solvent $N, N^{\prime}$-dimethylacetamide (DMAc, 99.8\% anhydrous, Aldrich) was used without further purification. All liquids used in solubility experiments were of reagent grade without further purification.

\section{Preparation of 6FDA-4,4'ODA Polyimide Film}

The poly(amic acid) (PAA, $15 \mathrm{wt} \%$ ) was prepared by solution polymerization of $4,4^{\prime} \mathrm{ODA}$ with stoichiometric amounts of $6 \mathrm{FDA}$ in DMAc at room temperature for $12 \mathrm{~h}$. PAA solution was coated on a glass substrate by a spin coater. The coated PAA was dried at $70^{\circ} \mathrm{C}$ in vacuum oven, and then final 6 FDA-4,4'ODA polyimide was obtained by thermal imidization at $350^{\circ} \mathrm{C}$ for $3 \mathrm{~h}$. The synthetic scheme of 6 FDA-4,4'ODA polyimide is shown in Figure 1.

\section{Imidization and Inherent Viscosity}

The infrared spectra of the PAA and polyimide were taken by a GENESIS FT-IR spectrophotometer. The inherent viscosity of PAA solution was measured at a concentration of $0.5 \mathrm{~g} \mathrm{dL}^{-1}$ in DMAc at $25^{\circ} \mathrm{C}$ by ubbelohde viscometer.

\section{Solubility Parameters}

Solubility Experiments. $0.3 \mathrm{~g}$ of 6 FDA-4,4'ODA polyimides were immersed in $5 \mathrm{~mL}$ of different liquids in sealed glass tubes at $25^{\circ} \mathrm{C}$ for 5 days. According to liquid ability to dissolve or swell the prepared polyimide, the solubility extent of the liquid was divided into four groups: solvent (S), good swelling liquid (GSL), poor swelling liquid(PSL), and nonsolvent (NS). The analytical total solubility of 6FDA-4,4'ODA polyimide was obtained from $\delta_{\mathrm{v}}\left(=\sqrt{\delta_{\mathrm{d}}^{2}+\delta_{\mathrm{p}}^{2}}\right.$, contribution of dispersion and polar forces to the solubility parameter) vs. $\delta_{\mathrm{h}}$ (contribution of hydrogen bonding to solubility) space diagram by Bagley et al. ${ }^{20}$

Equilibrium Swelling Method. Homogeneous 6FDA$4,4^{\prime}$ ODA polyimide films with thickness of $7-10 \mu \mathrm{m}$ were dried in vacuum oven at $130^{\circ} \mathrm{C}$ for several days, and after that weight of films was measured using a
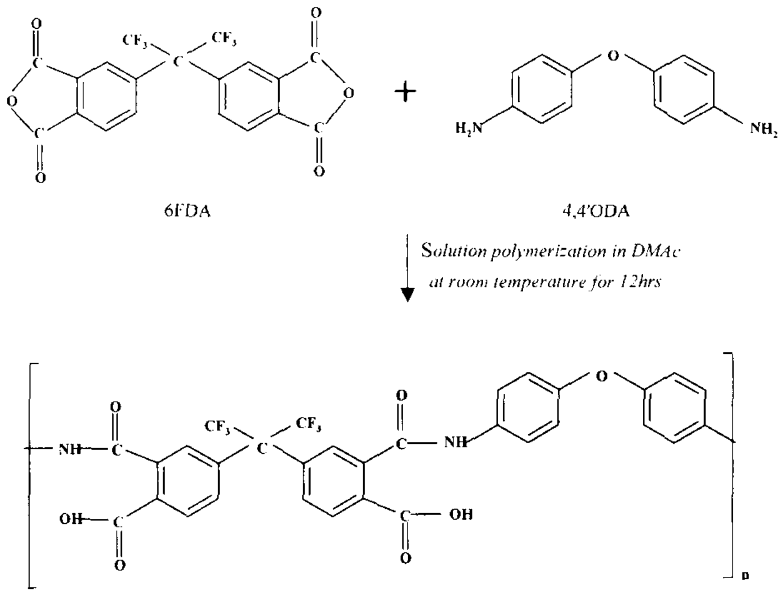

Polymer Solution (Poly amic acid)

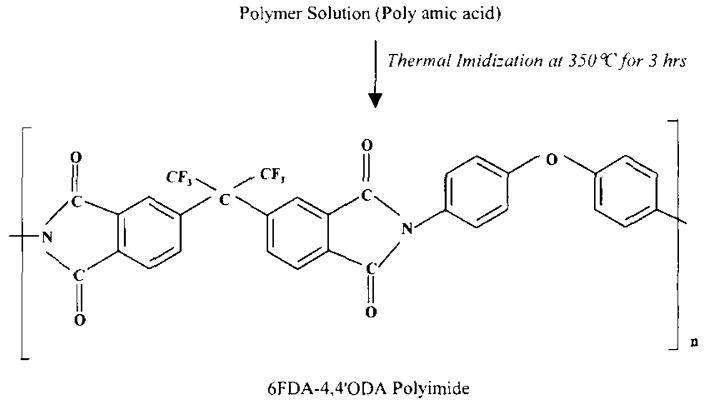

Figure 1. Synthetic scheme of 6 FDA-4,4'ODA polyimide.

digital balance. The films were immersed into a glass tube containing different ratios of water/acetone and water/acetic acid mixtures at $25^{\circ} \mathrm{C}$. The films were taken from the liquid mixtures after equilibrium swelling was reached (about 2 day), and wiped with filter paper. Finally, swelling was determined by measuring the weight increase between dry weight and swelling weight. The equilibrium swelling ratio expressed in percent was calculated according to the following equation. ${ }^{22}$

$$
\left(W_{\mathrm{s}}-W_{0}\right) / W_{0} \times 100 \%
$$

where $W_{\mathrm{s}}$ is the weight of the swollen film and $W_{0}$ is the dry weight of the film.

Group Contributions Method by Fedors. Theoretical methods could be used to evaluate solubility as well as experimental methods. The group contribution method was widely used. Based on an examination of many data on liquids, Fedors found that a general system for estimating both the cohesive energy and the molar volume could be set up simply. Therefore, the theoretical solubility of liquids and 6 FDA-4,4'ODA polyimide was easily obtained from Hansen table ${ }^{24}$ and Fedors method, ${ }^{16}$ respectively.

\section{RESULTS AND DISCUSSION}

\section{IR Spectra Analysis}

The infrared spectra of $6 \mathrm{FDA}-4,4$ ODA polyimide and PAA solution are shown in Figure 2. In the IR spectra of PAA, the absorbance band at $1660 \mathrm{~cm}^{-1}$ refers to the secondary amide group. In the IR spectra of 6 FDA-4,4' ODA polyimide, the band near $1780 \mathrm{~cm}^{-1}$ is attributed to the symmetric stretch of $\mathrm{C}=\mathrm{O}$ of the imide group. Ab- 


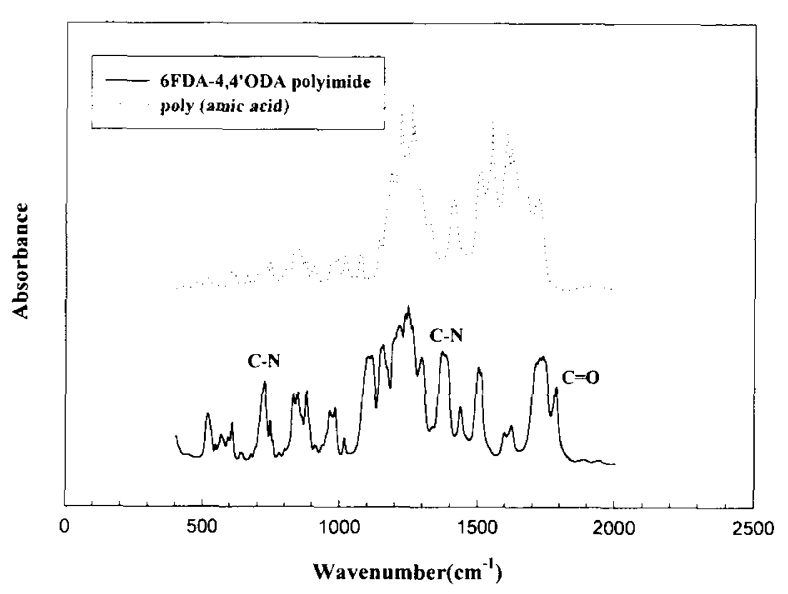

Figure 2. Infrared spectra of $6 \mathrm{FDA}-4,4$ 'ODA polyimide and poly(amic acid).

sorbance near $720 \mathrm{~cm}^{-1}$ and $1370 \mathrm{~cm}^{-1}$ is attributed to the $\mathrm{C}-\mathrm{N}$ stretch and to deformation of the imide ring or the imide carbonyl groups, respectively. Complete imidization was confirmed by comparison to the infrared spectra between the PAA solution and the polyimide. The inherent viscosity of PAA is $0.68 \mathrm{dL} \mathrm{g}^{-1}$ in DMAc.

\section{Total Solubility from Solubility Experiments}

Table I shows solubility ${ }^{24}$ and solubility extent of various liquids. As shown in Table I, six liquids are capable of completely dissolving 6FDA-4,4'ODA polyimide film. The Hansen method has the disadvantage that threedimensional structures are necessary for a graphical representation of the interaction between polymers and solvents. Therefore, the Bagley method representing a two-dimensional dimension is to be preferred for practical applications. Thus, in this study, each liquid used for the solubility experiments was represented as a point on a two-dimensional plot with $\delta_{\mathrm{v}}\left(=\sqrt{\delta_{\mathrm{d}}^{2}+\delta_{\mathrm{p}}^{2}}\right.$, contribution of dispersion and polar forces to the solubility parameter) and $\delta_{\mathrm{h}}$ (contribution of hydrogen bonding to the solubility parameter) as axes. For each axis a limited region has been considered by minimum and maximum values of the two components which are solvents and good swelling liquids. Numerical solubility in the twodimensional of $\delta_{\mathrm{v}}$ and $\delta_{\mathrm{h}}$ diagram was obtained by a computer iteration based on the least squares method using the Lingo 5 (Lindo system Inc.) as the optimum program.

The solubility of 6 FDA-4,4'ODA polyimide in various liquids in the $\delta_{\mathrm{v}}-\delta_{\mathrm{h}}$ diagram is shown in Figure 3 . The solubility region in the two-dimensional space is represented by a circle, best fitted by following equation :

$$
\left(\delta_{\mathrm{v}}-\delta_{\mathrm{v}, \mathrm{p}}\right)^{2}+\left(\delta_{\mathrm{h}}-\delta_{\mathrm{h}, \mathrm{p}}\right)^{2}=4.87
$$

For calculation of the optimized solubility region, initial condition were assumed as follows. First, $\delta_{\mathrm{v}, \mathrm{p}}$ and $\delta_{\mathrm{h}, \mathrm{p}}$ are larger than zero. The radius of a circle is small comparison to the maximum value of $\delta_{\mathrm{v}, \mathrm{p}}$ and $\delta_{\mathrm{h}, \mathrm{p}}$. The radius of a circle is larger than zero.

The solubility of $6 \mathrm{FDA}-4,4$ 'ODA polyimide was evaluated as follows : $\delta_{\mathrm{v}, \mathrm{p}}=20.14\left(\mathrm{~J} \mathrm{~cm}^{-3}\right)^{1 / 2}$ and $\delta_{\mathrm{h}, \mathrm{p}}=6.84$ $\left(\mathrm{J} \mathrm{cm}^{-3}\right)^{1 / 2}$. Total solubility, $\delta_{\mathrm{t}, \mathrm{p}}$ is $21.23\left(\mathrm{~J} \mathrm{~cm}^{-3}\right)^{1 / 2}$ after
Table I. Solubility $\left[\left(\mathrm{J} \mathrm{cm}^{-3}\right)^{1 / 2}\right]$ of liquids and solubility extent of 6 FDA-4,4'ODA polyimide

\begin{tabular}{|c|c|c|c|c|c|c|}
\hline Liquids & $\delta_{\mathrm{d}}$ & $\delta_{\mathrm{p}}$ & $\delta_{\mathrm{v}}$ & $\delta_{\mathrm{h}}$ & $\delta_{\mathrm{t}}$ & $\begin{array}{c}\text { Solubility } \\
\text { extent }\end{array}$ \\
\hline Acetone & 15.6 & 12.3 & 19.9 & 7.0 & 21.1 & NS \\
\hline Acetic acid & 14.5 & 8.0 & 16.6 & 13.5 & 21.4 & NS \\
\hline Acetic anhydride & 10.0 & 11.3 & 15.1 & 15.7 & 21.8 & PSL \\
\hline Acetaldehyde & 14.7 & 8.0 & 16.7 & 11.3 & 20.2 & PSL \\
\hline Acetonitrile & 15.3 & 18.0 & 23.6 & 6.1 & 24.4 & NS \\
\hline Acrylic acid & 13.5 & 12.8 & 18.6 & 17.9 & 25.9 & NS \\
\hline Acrylonitrile & 16.4 & 17.4 & 23.9 & 6.8 & 24.9 & PSL \\
\hline Aniline & 19.4 & 5.1 & 20.1 & 10.2 & 22.6 & $\mathrm{~S}$ \\
\hline Benzene & 18.4 & 0 & 18.4 & 2.1 & 18.6 & $\mathrm{NS}$ \\
\hline 1-Butanol & 16.0 & 5.7 & 17.0 & 15.8 & 23.1 & NS \\
\hline Chloroform & 17.8 & 3.1 & 18.1 & 5.7 & 19.0 & PSL \\
\hline Cychlohexane & 16.7 & 0.0 & 16.7 & 0.0 & 16.7 & PSL \\
\hline Cychlohexanol & 17.4 & 4.1 & 17.9 & 13.5 & 22.1 & PSL \\
\hline$\underline{m \text {-Cresol }}$ & 18.0 & 5.1 & 18.7 & 12.9 & 22.7 & GSL \\
\hline$N, N$-Dimethyl acetamide & 16.8 & 11.5 & 20.4 & 10.2 & 22.7 & GSL \\
\hline$N, N$-Dimethyl formamide & 17.4 & 13.7 & 22.1 & 11.3 & 24.8 & $\mathrm{~S}$ \\
\hline Dimethyl sulfoxide & 18.4 & 16.4 & 24.7 & 10.2 & 26.7 & $\mathrm{~S}$ \\
\hline Ethanol & 15.8 & 8.8 & 18.1 & 19.4 & 26.5 & NS \\
\hline Ethyl acetate & 15.8 & 5.3 & 16.7 & 7.2 & 18.1 & PSL \\
\hline Ethanol amine & 17.2 & 15.6 & 23.2 & 21.3 & 31.6 & GSL \\
\hline Ethylene dichloride & 18.8 & 5.3 & 19.5 & 4.1 & 19.6 & GSL \\
\hline thylene glycol & 17.0 & 11.1 & 20.3 & 26.0 & 33.0 & NS \\
\hline Diethyl ether & 14.5 & 2.9 & 14.8 & 5.1 & 15.8 & NS \\
\hline Dioctyl phtalate & 16.6 & 7.0 & 18.0 & 3.1 & 18.3 & PSL \\
\hline Glycerol & 17.4 & 12.1 & 21.2 & 29.3 & 36.2 & NS \\
\hline Methanol & 15.1 & 12.3 & 19.5 & 22.3 & 29.6 & NS \\
\hline$N$-Methyl-2-pyrrolidone & 18.0 & 12.3 & 21.8 & 7.2 & 22.9 & $\mathrm{~S}$ \\
\hline Methylene chloride & 18.2 & 6.4 & 19.3 & 6.2 & 20.3 & $S$ \\
\hline Nitrobenzene & 17.6 & 12.3 & 21.5 & 4.1 & 21.9 & PSL \\
\hline 1-Propanol & 16.0 & 6.8 & 17.4 & 17.4 & 24.6 & NS \\
\hline Propylene carbonate & 20.1 & 18.0 & 27.0 & 4.1 & 27.3 & GSL \\
\hline Propylene glycol & 16.8 & 9.4 & 19.3 & 23.3 & 19.5 & NS \\
\hline Pyridine & 19.0 & 8.8 & 20.9 & 5.9 & 21.8 & $\mathrm{~S}$ \\
\hline 2-Pyrrolidone & 19.5 & 17.4 & 26.1 & 11.3 & 28.5 & GSL \\
\hline Styrene & 18.6 & 1.6 & 18.7 & 4.1 & 19.1 & NS \\
\hline Toluene & 18.0 & 1.4 & 18.1 & 2.1 & 18.2 & NS \\
\hline Triethylene glycol & 16.0 & 10.4 & 19.1 & 18.6 & 27.5 & NS \\
\hline$o$-Xylene & 17.8 & 1.0 & 17.8 & 3.1 & 18.1 & PSL \\
\hline Water & 12.2 & 22.8 & 25.9 & 40.4 & 48.0 & NS \\
\hline
\end{tabular}

S : Solvent, GSL : Good swelling liquid, PSL : Poor swelling liquid, NS : Nonsolvent

calculation according to the following equation :

$$
\delta_{\mathrm{t}, \mathrm{p}}=\sqrt{{\delta_{\mathrm{v}, \mathrm{p}}{ }^{2}+\delta_{\mathrm{h}, \mathrm{p}}{ }^{2}}^{2}}
$$

\section{Total Solubility by Equilibrium Swelling Method}

The equilibrium swelling ratios of 6 FDA-4,4'ODA polyimide in mixtures of water/acetone and water/acetic acid at $25^{\circ} \mathrm{C}$ are shown in Table II. The solubility of liquid mixtures was calculated as follows : 


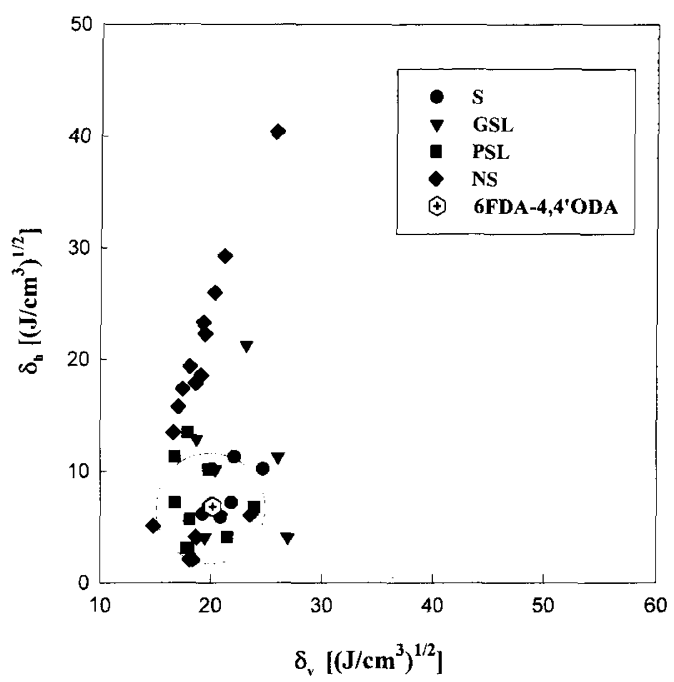

Figure 3. Solubility of 6 FDA-4,4'ODA polyimide in various liquids in the $\delta_{\mathrm{v}}-\delta_{\mathrm{h}}$ diagram.

Table II. Equilibrium swelling ratios of 6 FDA-4,4'ODA polyimide film in mixtures of water/acetone and water/acetic acid

\begin{tabular}{|c|c|c|c|c|c|c|c|c|}
\hline \multirow{3}{*}{$\begin{array}{l}\text { Mixtures } \\
\text { Values }\end{array}$} & \multicolumn{8}{|c|}{ Solvent (v/v) } \\
\hline & \multicolumn{4}{|c|}{ Water/acetone $(\mathrm{v} / \mathrm{v} \%)$} & \multicolumn{4}{|c|}{ Water/acetic acid (v/v\%) } \\
\hline & $3 / 97$ & $6 / 94$ & $9 / 91$ & $12 / 88$ & $3 / 97$ & $6 / 94$ & $9 / 91$ & $12 / 88$ \\
\hline $\begin{array}{l}\text { Equilibrium } \\
\text { swelling ratio } \\
(\%)\end{array}$ & 3.0 & 3.4 & 3.1 & 2.8 & 2.9 & 3.0 & 2.8 & 2.6 \\
\hline $\begin{array}{l}\text { Solubility } \\
\delta,\left(\mathrm{J} \mathrm{cm}^{-3}\right)^{1 / 2}\end{array}$ & 21.91 & 22.71 & 23.52 & 24.33 & 22.2 & 22.99 & 23.7 & 24.59 \\
\hline
\end{tabular}

$$
\delta=\sum_{\mathrm{i}} j_{\phi} i_{\delta}
$$

where $j_{\phi}$ is the volume fraction of $i$ species and $i_{\delta}$ is the solubility parameter of $i$ species.

The highest equilibrium swelling ratios are reached in $6 \% \mathrm{v} / \mathrm{v}$ water in acetone and $6 \% \mathrm{v} / \mathrm{v}$ in acetic acid, which correspond to total solubility of 22.71 and 22.99 $\left(\mathrm{J} \mathrm{cm}^{-3}\right)^{1 / 2}$, respectively. These results indicate that the $\delta_{\mathrm{t}, \mathrm{p}}$ is between 22.71 and $22.99\left(\mathrm{~J} \mathrm{~cm}^{-3}\right)^{1 / 2}$.

\section{Solubility of 6FDA-4,4'ODA by Fedors Method}

Several calculation methods using group contributions were applied to estimate the solubility parameters of polymer: the methods of Van Krevelen, ${ }^{25}$ Hoftyzer, ${ }^{15}$ Hoy, ${ }^{25}$ Small, ${ }^{25}$ and Fedors. ${ }^{16,25}$ Because accurate informations of 6 FDA-4,4'ODA polyimide are contained the Fedors table, the solubility of 6 FDA-4,4'ODA polyimide is estimated by Fedors method. The solubility parameter of high molecular weight polymer can be rewritten as,

$$
\delta=\left(\frac{\Sigma \Delta e_{\mathrm{Coh}, \mathrm{ii}}}{\Sigma \Delta v_{\mathrm{i}}}\right)^{1 / 2}=\left(\frac{\Delta E_{\mathrm{Coh}, \mathrm{i}}}{\Delta V_{\mathrm{i}}}\right)^{1 / 2}
$$

where $\Delta e_{C o h, \mathrm{i}}$ is additive atomic and group contributions of the cohesive energy and $\Delta v_{\mathrm{i}}$ is additive atomic and group contributions for the molar volume. The group contributions of $\Delta e_{\mathrm{Coh}, \mathrm{i}}$ and $\Delta v_{\mathrm{i}}$ were taken from Fedors method. ${ }^{25}$ The evaluation of 6 FDA-4,4'ODA polyimide solubility is shown in Table III. The total solubility parameter is $22.22\left(\mathrm{~J} \mathrm{~cm}^{-3}\right)^{1 / 2}$. A comparison of experimen-
Table III. Evaluation of solubility of 6FDA-4,4'ODA polyimide by Fedors's group contributions<smiles>Cc1ccc(Oc2ccc(N3C(=O)c4ccc(C(F)(F)c5ccc6c(c5)C(=O)N(C)C6=O)cc4C3=O)cc2)cc1</smiles>

\begin{tabular}{|c|c|c|c|}
\hline \multicolumn{2}{|r|}{ Structure } & $\Delta E_{\mathrm{Coh}, \mathrm{i}}$ & $\Delta V_{\mathrm{i}}$ \\
\hline \multicolumn{2}{|c|}{1} & 3350 & 3.8 \\
\hline \multicolumn{2}{|c|}{1} & 1470 & -19.2 \\
\hline 2 & \multirow[t]{2}{*}{$-\mathrm{CF}_{3}$} & 4270 & 57.5 \\
\hline 2 & & 31940 & 33.4 \\
\hline 2 & 0 & 31490 & 52.4 \\
\hline 4 & $-\mathrm{CO}-$ & 17370 & 10.8 \\
\hline 2 & & 4190 & -9.0 \\
\hline \multicolumn{2}{|c|}{$\begin{array}{l}\text { Ring closure } 5 \\
\text { or more atoms }\end{array}$} & 1050 & 16 \\
\hline \multirow[t]{2}{*}{32} & Skeletal atoms & - & 2 \\
\hline & SUM & 225280 & 456.4 \\
\hline \multicolumn{4}{|c|}{$\delta=\left(\frac{\Delta E_{\mathrm{Coh}, \mathrm{i}}}{\Delta V_{\mathrm{i}}}\right)^{1 / 2}=(225280 / 456.4)^{1 / 2}=22.22\left(\mathrm{~J} \mathrm{~cm}^{\cdots 3}\right)^{1 / 2}$} \\
\hline
\end{tabular}

6FDA-4,4'ODA Polyimide

Table IV. Comparison of the solubility $\left[\left(\mathrm{J} \mathrm{cm}^{-3}\right)^{1 / 2}\right]$ of 6 FDA-4,4'ODA polyimide by experimental and

\begin{tabular}{|c|c|c|c|c|c|c|}
\hline $\mathrm{Me}$ & thod & $\delta_{\mathrm{d}, \mathrm{p}}$ & $\delta_{\mathrm{p}, \mathrm{p}}$ & $\delta_{\mathrm{v}, \mathrm{p}}$ & $\delta_{\mathrm{h}, \mathrm{p}}$ & $\delta_{t, \mathrm{p}}$ \\
\hline \multirow{2}{*}{ Experimental } & $\begin{array}{l}\text { Solubility } \\
\text { experiments }\end{array}$ & & - & 20.14 & 6.84 & 21.23 \\
\hline & $\begin{array}{l}\text { Equilibrium } \\
\text { swelling method }\end{array}$ & - & - & - & 一 & $\begin{array}{l}22.71- \\
22.99\end{array}$ \\
\hline Theoretical & $\begin{array}{l}\text { Fedors } \\
\text { group contributions }\end{array}$ & - & - & - & - & 22.22 \\
\hline
\end{tabular}
theoretical methods

tal and calculated solubility parameters of 6 FDA-4,4'ODA polyimide is represented in Table IV. The results of the Fedors and equilibrium swelling methods are in very good agreement, but the solubility of solubility experiments was a little higher than that of the solubility experiments. This is explained by the limited choice of solvents in solubility experiments. According to the solvents and good swelling liquids, the solubility of polymer changes and solubility is flexible. In this solubility experiment, it can be obtained more accurately if more solvents are allowed in Hansen data. Therefore, to obtain more accurately the solubility of a polymer, it should be determined by several methods through the theoretical and experimental procedures, and comparison of the data. 


\section{CONCLUSIONS}

Alteration of the solubility of 6 FDA-4,4'ODA polyimide was investigated through experimental (solubility experiments and equilibrium swelling method) and theoretical (group contribution method by Fedors) methods. From the $\delta_{\mathrm{v}}\left(=\sqrt{\delta_{\mathrm{d}}^{2}+\delta_{\mathrm{p}}^{2}}\right.$, contribution of dispersion and polar forces to the solubility parameter) vs. $\delta_{\mathrm{h}}$ (contribution of hydrogen bonding to the solubility parameter) diagram, the total solubility of 6 FDA-4,4'ODA polyimide was found to be $21.23\left(\mathrm{~J} \mathrm{~cm}^{-3}\right)^{1 / 2}$. Total solubility determined from the equilibrium swelling method was between 22.71 and $22.99\left(\mathrm{~J} \mathrm{~cm}^{-3}\right)^{1 / 2}$. Total solubility of a 6 FDA-4,4'ODA polyimide calculated from the Fedors method by group contributions was $22.22\left(\mathrm{~J} \mathrm{~cm}^{-3}\right)^{1 / 2}$. Total solubility according to the experimental methods showed little discrepancy from theoretical values. To obtain more accurately the solubility of a polymer, it should be determined by several methods through theoretical and experimental procedures, a comparison of the results.

\section{REFERENCES}

1. M. A. M. Beerlage, Ph. D. Thesis, Netherlands : Enschede, 1994.

2. K. Y. Chun, H. S. Kim, H. S. Han, and Y. I. Joe, J. of Korean Ind. \& Eng. Chem., 9, 306 (1998).

3. K. A. Lokhandwala, S. M. Nadakatti, and S. A. Stern, J. of Polym. Sci. : Part B : Polym. Phys., 33, 965 (1995).

4. M. R. Coleman and W. J. Koros, J. of Polym. Sci. : Part B Polym. Phys., 32, 915 (1994).

5. Y. Hirayama, T. Yoshinaga, Y. Kusuki, K. Ninomiya, T. Sakakibara, and T. Tamari, J. of Membrane Sci., 111, 169 (1996).

6. K. Y. Chun, H. S. Han, and Y. I. Joe, HWAHAK KONGHAK, 35, 928 (1997).

7. F. C. Lin, D. M. Wang, and J. Y. Lai, J. of Membrane Sci., 110, 25 (1996).

8. J. Y. Lai, F. C. Lin, C. C. Wang, and D. M. Wang, J. of Membrane Sci., 118, 49 (1996).

9. K. Y. Chun, S. W. Lee, H. S. Han, and Y. I. Joe, Theories and Application of Chem. Eng., 4, 3169 (1998).

10. K. Y. Chun, H. S. Kim, H. S. Han, Y. G. Shul, and Y. I. Joe, HWAHAK KONGHAK, 37, 262 (1999)

11. J. Hilderbrand and R. Scott, "The Solubility of Nonelectrolytes", 3rd ed, Reinhold Publ. Corp., New York, N.Y., 1949 , pp 12-15.

12. M. Z. Dunkel, Physik. Chem., A138, 42 (1928).

13. R. A. Hayes, J. Appl. Polym. Sci., 5, 318 (1961).

14. A. T. Di Benedetto, J. Polym. Sci., Al, 3459 (1963)

15. P. J. Hoftyzer and D. W. Van Krevelen, presented at the International Symposium on Macromolecules of IUPAC, Ley- den, 1970 .

16. R. F. Fedors, Polym. Eng. Sci., 14, 147 (1974).

17. A. Beerbower, L. A. Laye, and D. A. Pattison, Chem. Eng., 118 (1967).

18. W. Gordy and S. C. Stanford, Chem. Phys., 7, 93 (1939)

19. C. M. Hansen, J. Paint Tech., 39, 104 (1967).

20. E. B. Bagley, T. P. Nelson, and J. M. Scigliano, J. Paint Tech., 43, 35 (1971)

21. D. Mangaraj, S. K. Bhatnagar, and J. B. Rath, Makromol. Chem., 67, 75 (1963).

22. A. Chapiro, Z. Mankowiski, and N. Schmitt, J. Polym. Sci., Polym. Chem. Ed., 20, 1971 (1982).

23. J. Fuehrer, Ph. D. Dissertation, University of Cologne, 1980.

24. F. M. Allan and M. Barton, "CRC Handbook of Solubility Parameters and other Cohesion Parameters", 2nd ed, CRC Press, Boca Raton, FL, 1985, pp 94-110.

25. D. W. Van Krevelen, "Properties of Polymers", 3rd ed, Elservier Science, Amsterdam, 1990, pp 189-225.

\section{APPENDIX : VARIABLES AND ABBREVIATION}

$\delta_{\mathrm{d}} \quad$ Contribution of dispersion force to the solubility $\left(\mathbf{J}^{1 / 2}\left(\mathrm{~cm}^{-3}\right)^{1 / 2}\right)$

$\delta_{\mathrm{d}, \mathrm{p}} \quad$ Contribution of dispersion force to the solubility of polymer $\left(\mathrm{J}^{1 / 2}\left(\mathrm{~cm}^{-3}\right)^{1 / 2}\right)$

$\delta_{\mathrm{h}} \quad$ Contribution of hydrogen bonding force to the solubility $\left(\mathrm{J}^{\mathrm{1} / 2}\left(\mathrm{~cm}^{-3}\right)^{1 / 2}\right)$

$\delta_{\mathrm{h}, \mathrm{p}} \quad$ Contribution of hydrogen bonding force to the solubility of polymer $\left(\mathrm{J}^{1 / 2}\left(\mathrm{~cm}^{-3}\right)^{1 / 2}\right)$

$\delta_{\mathrm{p}} \quad$ Contribution of polar force to the solubility $\left(\mathrm{J}^{1 / 2}\right.$ $\left.\left(\mathrm{cm}^{-3}\right)^{1 / 2}\right)$

$\delta_{\mathrm{p}, \mathrm{p}} \quad$ contribution of polar force to the solubility of polymer $\left(\mathrm{J}^{1 / 2}\left(\mathrm{~cm}^{-3}\right)^{1 / 2}\right)$

$\delta_{\mathrm{v}} \quad \sqrt{\delta_{\mathrm{d}}^{2}+\delta_{\mathrm{p}}^{2}}$, Contribution of dispersion and polar force to the solubility $\left(\mathrm{J}^{1 / 2}\left(\mathrm{~cm}^{-3}\right)^{1 / 2}\right)$

$\Delta v \quad$ Hydrogen bonding number

$\Delta e_{\text {Coh,i }}$ Additive atomic and group contributions of the cohesive energy $(\mathrm{J})$

$E_{\text {coh,i }}$ Cohesive energy of component i $\left(\mathrm{J}^{1 / 2} \mathrm{~cm}^{-3}\right)$

$\mathrm{i}_{\delta} \quad$ Solubility of i species $\left(\mathrm{J}^{1 / 2}\left(\mathrm{~cm}^{-3}\right)^{1 / 2}\right)$

$j_{\phi} \quad$ Volume fraction of $i$ species $(\%)$

$\Delta U_{\mathrm{V}, \mathrm{i}} \quad$ Energy of vaporization $(\Delta U)$ unit volume of $\mathrm{i}(\mathrm{J})$

$\Delta v_{i} \quad$ Additive atomic and group contributions for the molar volume $\left(\mathrm{cm}^{3}\right)$

$V_{\mathrm{i}}^{0} \quad$ Unit volume of $\mathrm{i}\left(\mathrm{cm}^{3}\right)$

$W_{\mathrm{s}} \quad$ Weight of the swollen film $(\mathrm{g})$

$W_{0} \quad$ Dry weight of the film (g)

S Solvent

GSL Good swelling liquid

PSL Poor swelling liquid

NS Nonsolvent 